\title{
Promoting Vulgarity by Teaching Slang in the Classroom
}

By: David A. Fein

Fein, David A. "Promoting Vulgarity by Teaching Slang in the Classroom.” Rocky Mountain Review, 65.1 (2011): n.pag. Web. 02 Mar. 2015.

Made available courtesy of the Rocky Mountain Modern Language Association (RMMLA): http://www.rmmla.org/ereview/65.1/articles/fein.asp

\section{***(C) RMMLA. Reprinted with permission. No further reproduction is authorized without written permission from RMMLA. This version of the document is not the version of record. Figures and/or pictures may be missing from this format of the document. ***}

\section{Abstract:}

Mark Twain once said, "Indecency, vulgarity, obscenity -- these are strictly confined to man; he invented them. Among the higher animals there is no trace of them." I would like to suggest that we, as language teachers, need to be a little more open to the vulgar vernacular. I use "vulgar" in its original sense -- "common, ordinary" -- from the Latin vulgaris, "of or pertaining to the common people." Essentially, then, I wish to argue that we need to teach our students the use more vulgarity in their speech.

Keywords: Foreign language education | Vernacular language | Slang

\section{Article:}

Mark Twain once said, "Indecency, vulgarity, obscenity -- these are strictly confined to man; he invented them. Among the higher animals there is no trace of them." I would like to suggest that we, as language teachers, need to be a little more open to the vulgar vernacular. I use "vulgar" in its original sense -- "common, ordinary" -- from the Latin vulgaris, "of or pertaining to the common people." Essentially, then, I wish to argue that we need to teach our students the use more vulgarity in their speech.

Since my interest relates to language teaching in general, and not only to French, which is the language I happen to teach, many of my examples will be taken from American slang for purposes of illustration. The distinction between colloquialism and slang is not at all clear. Colloquial expression, of course, covers a wide spectrum of language usage, of which slang is a sub-category. As language teachers, most of us can instinctively and fairly confidently place various examples in one category or another. We might generally agree that "to drink someone under the table" is a colloquialism and to "get loaded," "soused," "smashed," "pickled" or "plastered" are all good examples of slang. There are, of course, more crude expressions, which we all know very well and which I have deliberately omitted. I am not, by the way, advocating that we acquaint our students with obscene slang. We should have confidence, indeed complete 
confidence, in our students' ability to acquaint themselves with this language, on their own, and under circumstances that we may prefer not to imagine, once they are immersed in another culture.

Many of us are reluctant to include slang as a regular feature of our language teaching, and perhaps with good reason. Let me play the devil's advocate for a moment and briefly outline a few reasons to avoid the teaching of slang.

1) We obviously need to recognize our own limitations as language teachers. It is simply a fact that many of us who are not absolutely bilingual will not be completely familiar with certain slang expressions that we may have heard but have not transferred to our active vocabulary. In fact, I readily admit that there are many slang terms in American English that I would be unable to define, especially those related to popular music, youth culture, and various ethnic groups. We may, therefore, consider ourselves, to a certain degree, to be slang-deficient, slang-illiterate.

2) We know that many slang terms are highly perishable. Will students be carrying around in their linguistic luggage, for the rest of their lives, terms that have will have long since disappeared from common usage? We imagine them years from now trying to impress some bewildered native-speaker with remnants of the slang they have retained from their formal study of the language, using the equivalent of expressions such as "the cat's meow," "the cat's pajamas," "the bees' knees."

3) We may worry that students will use slang inappropriately. Slang terms may start to show up in their formal writing, or they may slip out during interviews or any other social situations where they would be considered inappropriate. Instead of saying that a soccer team played surprisingly well against a formidable opponent, our students, in a moment of unguarded enthusiasm, may fall back on a more familiar vernacular and say that the team "kicked ass."

4) We, as language teachers, as those who set the basic standards for acceptable language use, may simply have a hidden bias against teaching slang. Or we may believe that slang belongs to an area of cultural experience that lies outside the limits of the classroom. We may assume, and there is a certain logic to this assumption, that slang is best taught by those who use it the most in the places where it is used most frequently -- that is, by student peers in the street, in bars, at parties, etc. Why waste valuable class time on vocabulary of dubious value that students will inevitably pick up on their own?

Let me now briefly address each of these arguments.

1) We may not feel comfortable teaching slang, given our own limitations in this area. Slang belongs to a vernacular that many of us may understand but which we do not speak on a regular basis. We may not be the ones best qualified to teach it. On the other hand, we can feel comfortable with widely accepted and widely circulated slang terms that our students are likely to hear repeatedly once they are immersed in the target culture. For example, we can teach our 
students an alternative to "Je n'ai pas d'argent" ["I have no money"]. Instead they can say, "Je suis fauché" ["I'm broke"]. This is a very useful phrase. It's probably one they will be using often in France. By choosing judiciously, we can easily compile a relatively modest collection of highusage slang terms that students will have ample opportunity to employ.

2) We know that many slang terms drop out of fashion very quickly. We should therefore avoid slang that has only come into usage quite recently and whose life expectancy may be very limited. My own preference, when selecting French slang to teach -- and I do select very carefully -- is to limit myself mainly to "classic" terms that have stood the test of time. Going back to the list of slang synonyms for drunk, the term "loaded" has actually been in usage for over a century, with its first recorded appearance in 1890. This kind of well-established slang is one that students can use confidently to enrich their vocabulary, widen their range of expression, and impress their friends when they describe their escapades of the previous evening.

3) We worry that students will use slang inappropriately. There are two points to consider here. First, assuming that students will acquire a certain amount of slang from other sources, if not as part of their formal language instruction, there is always the risk that it will be used inappropriately in certain social situations. If, on the other hand, the slang vocabulary is taught in conjunction with more widely acceptable terms, they can be made aware of the difference. (For example, "Attention!" and "Fais gaffe!" both mean "Look out!" or "Be careful!" The first might be used to warn a stranger on the street of some impending danger; the second would be used among close acquaintances in the same situation.) This awareness effectively provides the student with a range of expression, depending on the social context. Second, students often have difficulty distinguishing between formal and informal registers even within their own language. Having recently taught a freshman seminar in English, I noticed when evaluating student essays that one of the corrections I found myself making most often related to the inappropriate use of colloquial expressions in the context of formal writing.

(4) We, as language teachers, have no business teaching slang. Our job is to teach students to manipulate the basic grammatical structures, idioms, and vocabulary. Anything else they can acquire on their own. Rather than answer this objection myself, I'll let the students answer. I recently asked students in one of our advanced French classes to complete a survey on the acquisition and usage of slang. Some students had studied in France, others had not. Almost all of them, however, demonstrated a strong interest in expanding their knowledge of French slang. Here are a few sample comments:

It better prepares students so that they can understand and communicate with native speakers.

Being able to understand and speak using slang allows for quicker relation between students and also may make the American student feel more comfortable with French peers.

Because we are so strongly encouraged to study abroad, it would be helpful to not sound like a textbook, and also to be able to understand what people are saying. 
Clearly what students are telling us is that they would like to be introduced to at least a few slang terms that they are likely to hear and use during their stay abroad.

In one of my French classes, a bridge course connecting the intermediate to the advanced level, I have experimentally introduced a little slang as part of the vocabulary that students are required to learn. Examples include:

bosser -- to work very hard

le fric -- money

bouffer -- to eat (often to eat excessively)

une clope -- a cigarette

un flic -- a cop

These are all terms that they will be hearing frequently during their stay in France, or if they spend time with French students in the States. They will occasionally, we trust, be working very hard ["bosser"]; they will occasionally need to borrow money ["le fric"]; etc. The terms I have just listed are strictly slang. In addition, I include a number of colloquialisms, but, as already indicated, the line of demarcation separating colloquialism from slang is often very difficult to draw. Students are expected to learn the meaning of these terms through any means they wish. Some are in contact with native-speakers, either French students enrolled in our university or contacts they have made while in France. Others may choose to consult an online dictionary. I encourage students to Google the terms, examine various examples of their usage by nativespeakers, and to try to extrapolate their meaning from the context.

The guidelines I follow in selecting French slang are fairly straightforward. Terms that have only come into usage very recently are best avoided. Terms that are generally considered obscene or offensive should obviously be avoided, as should those that have generally fallen out of usage. It might be helpful to think of the type of American slang that we would recommend teaching to ESL students in order to help them assimilate useful language that they are likely to be hearing in everyday conversations, on television, in movies (keeping in mind, of course, that their primary source will be their peers, and much of what they learn from this source will not be considered suitable for the classroom). Obviously, students can learn to speak perfectly acceptable English without any recourse to slang, but familiarity with high-usage slang terms will significantly widen their comprehension, enrich their speech, and provide them with colorful and emphatic means of expression, using terms such as "bazillion," "dorky," "uptight," "laid back," and (one of my favorites) "humungous."

Without a doubt, the most effective way to learn slang is by experiencing it firsthand. As language teachers, the slang that we ourselves have learned is mainly associated with our own experience. In my case, during my first contact with France, as an American student studying in Nice, I had the misfortune of unexpectedly finding myself in the company of French student protesters who had taken refuge in a university dormitory after breaking some classroom 
windows and fleeing the police during a political demonstration. I was consequently arrested with the other protestors, placed in a police van and transported to the police station where I was booked, questioned, and eventually released. At some point during the ride to the police station, I heard someone, maybe a student or quite possibly a policeman, refer to the police van as a "panier à salade," literally a salad basket, but the slang equivalent of a "paddy wagon." Although I'm not sure that I've ever had the opportunity to actually use the term since that time, it has stayed with me in the many years that followed this incident, permanently filed in my memory, along with other unpleasant recollections from that night when I was given a very effective introduction to the French judicial system, where one is presumed guilty until proven innocent. Culturally and linguistically, however, it turned out to be a valuable lesson, and one that I wish all of our students could experience.

Ideally, then, I would like to see all of our students arrested, taken away in a police van, and charged with crimes they did not commit in order that they might deepen their cultural experience and expand their slang vocabulary. As a compromise, however, I have a few modest suggestions for ways in which we might broaden our language teaching to expand our students' linguistic horizons and better prepare them for their experience abroad.

1) We could systematically dedicate some class time (in conjunction with preparation outside of class) to slang vocabulary, a relatively small percentage of class time, but, nevertheless, a regular feature of the class.

2) Rather than present definitions of the vocabulary, I suggest that we send the students on a scavenger hunt. They should be encouraged to avail themselves of native-speakers, online dictionaries, and various Internet sources.

3) We should help students develop a sense of linguistic boundaries so that they will understand when it is appropriate or inappropriate to use certain slang terms, at the same time helping them develop an appreciation for the ways in which a language is enriched by slang terms, many of which are rather whimsical, humorous, even poetic (the term "panier à salade," for example).

Let's remember that our students don't want to go to France, Germany, or Spain, and sound like a textbook (to quote one of the student comments cited earlier). They want to be converse naturally with native speakers, especially those their own age. They don't want to appear uptight or dorky. They want to feel laid back. They want to have a humungous list of new friends on Facebook. They want to have a bazillion new friends. And they want their peers to be impressed by their command of the vernacular. They want them to be absolutely blown away, blown out of the water. They want to go to France, Germany, or Spain, and kick ass. Let's help them do it.

David A. Fein (Ph.D. Cornell) has been teaching French at the University of North Carolina at Greensboro since 1976. He has served in various administrative capacities including Head of the 
Department of Romance Languages, Associate Head, and Co-Director of the UNCG Summer Program in France. His fields of research include pedagogy and medieval literature. 